\title{
Oqtans: a Galaxy-integrated workflow for quantitative transcriptome analysis from NGS Data
}

\author{
Sebastian J Schultheiss ${ }^{1 *}$, Géraldine Jean ${ }^{1}$, Jonas Behr ${ }^{1}$, Regina Bohnert ${ }^{1}$, Philipp Drewe ${ }^{1}$, Nico Görnitz ${ }^{1,2}$, \\ André Kahles ${ }^{1}$, Pramod Mudrakarta', Vipin T Sreedharan', Georg Zeller ${ }^{1,3}$, Gunnar Rätsch ${ }^{1}$ \\ From Seventh International Society for Computational Biology (ISCB) Student Council Symposium 2011 \\ Vienna, Austria. 15 July 2011
}

\section{Background}

The current revolution in sequencing technologies allows us to obtain a much more detailed picture of transcriptomes via RNA-Sequencing. We have developed the first integrative online platform, oqtans, for quantitatively analyzing RNA-Seq experiments. Our approach of providing a self-contained machine image with the accessible, transparent Galaxy framework [1] minimizes the risk of using a third-party web service for data analysis. These services often disappear a few years after publication and render results irreproducible [2]. With oqtans, bioinformatics becomes reproducible by providing analysis building blocks for a customized workflow of read mapping, transcript reconstruction and quantitation as well as differential expression analysis.

\section{Method}

Oqtans includes a comprehensive machine-learningpowered toolsuite developed by the authors for NGS data analysis. PALMapper is a short-read mapper which efficiently computes both unspliced and spliced alignments at high accuracy by taking advantage of base quality information and computational splice site predictions [3]. mTIM is a transcript reconstruction method, which exploits features derived from RNA-seq read alignments and from computational splice site predictions to infer the exon-intron structure of the corresponding transcripts. rQuant is based on quadratic programming. It simultaneously estimates biases

\footnotetext{
* Correspondence: sebastian@bioweb.me

${ }^{1}$ Machine Learning in Biology Group, Friedrich Miescher Laboratory of the Max Planck Society, 72076 Tübingen, Germany

Full list of author information is available at the end of the article
}

inherent in library preparation, sequencing, and read mapping, and accurately determines the abundances of given transcripts [4]. rDiff is a set of statistical test techniques that determine significant differences between two RNA-seq experiments to find differentially expressed regions with or without knowledge of transcripts.

\section{Results}

We compare predictions to the published annotation at the intron and transcript levels. The performance of read aligners is shown in Fig. 1A from D. melanogaster data, and transcript segmentation tools in Fig. 1B, on C. elegans. Our tools, PALMapper and mTIM, outperform TopHat [5] and Cufflinks [6]. Oqtans is available free and open-source, from http://oqtans.org as a virtual machine for cloud computing environments, and ready

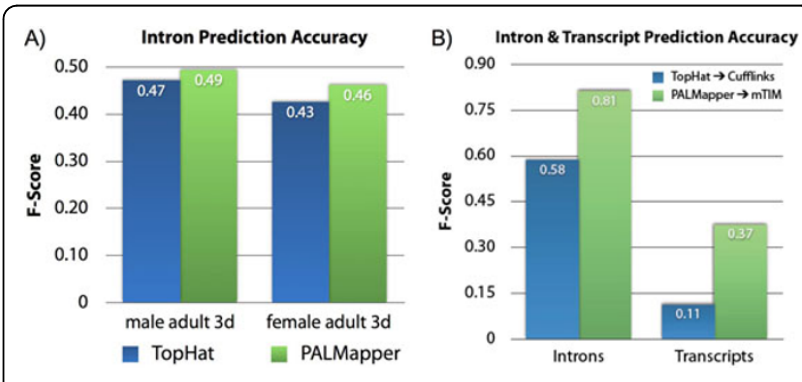

Figure 1 A) Accuracy (F-score) of intron predictions in 3-day-old adults of D. melanogaster with aligners PALMapper (green) and TopHat (blue). B) Accuracy of intron predictions with the same aligners and transcript predictions with MTIM (green) and Cufflinks (blue) on C. elegans RNA-seq transcriptome data.

\section{C)

(c) 2011 Schultheiss et al; licensee BioMed Central Ltd. This is an open access article distributed under the terms of the Creative Commons Attribution License (http://creativecommons.org/licenses/by/2.0), which permits unrestricted use, distribution, and reproduction in any medium, provided the original work is properly cited. 
to use on our public compute cluster at http://bioweb. $\mathrm{me} / \mathrm{mlb}$-galaxy.

\section{Author details}

${ }^{1}$ Machine Learning in Biology Group, Friedrich Miescher Laboratory of the Max Planck Society, 72076 Tübingen, Germany. ${ }^{2}$ Department of Software Engineering and Theoretical Computer Science, Technical University Berlin, 10578 Berlin, Germany. ${ }^{3}$ Structural and Computational Biology Unit,

European Molecular Biology Laboratory, 69117 Heidelberg, Germany.

Published: 21 November 2011

\section{References}

1. Goecks J, Nekrutenko A, Taylor J: Galaxy: a comprehensive approach for supporting accessible, reproducible, and transparent computational research in the life sciences. Genome biology 2010, 11(8):R86.

2. Schultheiss SJ, Münch MC, Andreeva GD, Rätsch G: Persistence and Availability of Web Services in Computational Biology. PLoS computational biology 2011, 6(9):e24914.

3. Jean G, Kahles A, Sreedharan VT, De Bona F, Ratsch G: RNA-Seq read alignments with PALMapper. In Current protocols in bioinformatics Andreas D Baxevanis [et al] 2010, Chapter 11:Unit 1116.

4. Bohnert R, Ratsch G: rQuant.web: a tool for RNA-Seq-based transcript quantitation. Nucleic acids research 2010, 38(Web Server):W348-351.

5. Trapnell C, Pachter L, Salzberg SL: TopHat: discovering splice junctions with RNA-Seq. Bioinformatics 2009, 25(9):1105-1111.

6. Roberts A, Trapnell C, Donaghey J, Rinn JL, Pachter L: Improving RNA-Seq expression estimates by correcting for fragment bias. Genome biology 2011, 12(3):R22.

doi:10.1186/1471-2105-12-S11-A7

Cite this article as: Schultheiss et al:: Oqtans: a Galaxy-integrated workflow for quantitative transcriptome analysis from NGS Data. BMC Bioinformatics 2011 12(Suppl 11):A7.

\section{Submit your next manuscript to BioMed Central and take full advantage of:}

- Convenient online submission

- Thorough peer review

- No space constraints or color figure charges

- Immediate publication on acceptance

- Inclusion in PubMed, CAS, Scopus and Google Scholar

- Research which is freely available for redistribution

Submit your manuscript at www.biomedcentral.com/submit
Biomed Central 